\title{
Mitteilung von der Generalversammlung der Schweizerischen Gesellschaft für Phlebologie (SGP)
}

\section{Samstag 9.6.2018 $1615-1700$ Uhr, Hotel Hilton, Strasbourg, Salle Orangerie D \\ Ehrung für die Verdienste für die VENALPINA}

Anlässlich der aktuellen Generalversammlung der SGP vom 09.06.2018 übergibt Christina Jeanneret die Venalpina-Ehrennadel an Stefan Küpfer. Bei dieser Gelegenheit wird Stefan Küpfer für seine ausserordentlichen Verdienste zugunsten der Venalpina von allen anwesenden Mitgliedern mit einem grossen Applaus verdankt.

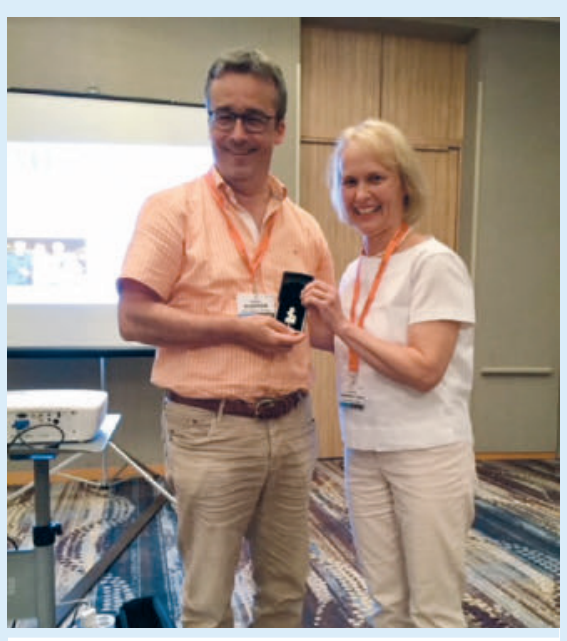

Stefan Küpfer wird mit der silbernen Venalpina Nadel geehrt (Foto: Ch. Jeanneret)

\section{IMPRESSUM}

Verantwortlich für Mitteilungen der SGP:

Prof. Dr. med. Christina Jeanneret-

Gris, Bruderholz 